\title{
Carnets
}

Revue électronique d'études françaises de l'APEF

Première Série - 3| 2011

$\mathrm{L}^{\prime}($ In)vraisemblable

\section{Um faro para a modernidade: breves notas sobre o (s) outro(s) mundo(s) de Cyrano de Bergerac}

\author{
Leila de Aguiar Costa
}

\section{(2) OpenEdition}

Journals

\section{Edição electrónica}

URL: http://journals.openedition.org/carnets/5868

DOI: 10.4000/carnets.5868

ISSN: 1646-7698

\section{Editora}

APEF

Edição impressa

Data de publição: 2 Janeiro 2011

Paginação: 33-48

Refêrencia eletrónica

Leila de Aguiar Costa, « Um faro para a modernidade: breves notas sobre o(s) outro(s) mundo(s) de Cyrano de Bergerac », Carnets [Online], Première Série - 3 | 2011, posto online no dia 18 junho 2018, consultado o 21 abril 2019. URL : http://journals.openedition.org/carnets/5868; DOI : 10.4000/ carnets.5868

Este documento foi criado de forma automática no dia 21 Abril 2019.

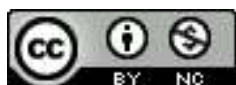

Carnets est mis à disposition selon les termes de la licence Creative Commons - Atribution - Pas d'utilisation commerciale 4.0 International. 


\title{
Um faro para a modernidade: breves notas sobre o(s) outro(s) mundo(s) de Cyrano de Bergerac
}

\author{
Leila de Aguiar Costa
}

La pointe n'est pas d'accord avec la raison, c'est

l'agréable jeu de l'esprit.

Cyrano de Bergerac

1 Em um século habitado, quiçá assombrado, por preceitos poéticos herdados da Antiguidade, a obra de Cyrano de Bergerac parece inscrever-se na contramão de toda normativa escritural ${ }^{1}$. A frase em exergo presta-se, assim, a paradigma de uma produção discursiva que se pretende e se quer moderna: protagonista neste século XVII, a razão para Bergerac é, pelo contrário, intrusa, mal-vinda e se torna, se se permitir a expressão, a personagem trouble fête.

2 Não surpreende, pois, que o Prefácio de Les Entretiens Pointus (1662) assuma logo à entrada seu partido: metamorfosear a linguagem, sobre a qual se faz pesar forte suspeita, resgatando-a de todo seu aparato retórico para mergulhá-la no registro do jogo e do deleite. Sentido posto em derrisão, coisas reduzidas a seus agréments, o que interessa à voz autoral é o brilho que se empreende ao discurso. 0 alvo? Platão e Aristóteles, mas também, por que não, Descartes e Pascal que poderiam perfeitamente se confundir, façase aqui a hipótese, com o "Pedant in sacris", com aquele "barbare maistre d'Escole" a que se refere a voz enunciativa da Lettre Satyrique XIII. Contre un Pedant ${ }^{2}$ (Bergerac, 1977: 98).

3 Razão que se opõe à pointe ${ }^{3}$. Razão que, por isso mesmo, opõe-se à poiesis. E, no centro da oposição, a noção de verossimilhança e os constrangimentos que impõem à invenção poética. Eis porque L'Autre Monde ratifica aquele viés anti-aristotélico e anti- platônico que se contrapõe, em Les Entretiens Pointus, ao universo fechado e finito dos Antigos: ali se desenha um universo sem limites, uma confusão sem fim do Espaço e do Tempo.

4 Texto publicado postumamente, em 1657, L'Autre Monde compõe-se de duas partes: “L'Autre Monde ou les Estats et Empires de La Lune" e "L'Autre Monde ou les Estats et Empires du Soleil". À semelhança, mas no interior mesmo da dessemelhança, o que se lê 
em uma e outra parte é o percurso iniciático de uma personagem que, segundo um modelo de narrativa de viagem, descobre outros mundos e outros seres. Diversos. Longe da terra. Na Lua e no Sol, em pleno século XVII. L'Autre Monde, seus Estats e seus Empires parecem pertencer ao registro do genus phantasticum, afastando-se, por conseguinte, do verossímil apregoado pelos Antigos e de sua preceptiva a respeito do genus icasticum.

Bem que sobejamente conhecidas, importa brevemente revisitar noções que circunscreviam o gênero fantástico e o gênero icástico, pois que uma e outra definição estão no cerne de uma mais ampla, aquela sobre as artes de imitação, regidas como se sabe pelo conceito balizar de imagem ou, se se preferir, de figuração e de simulacro. Relembre-se que para Aristóteles, a imagem exterior deve, sempre, estar em consonância inteligível com a imagem interna. Isto equivale a dizer que, aristotelicamente pensadas, as imagens nunca se libertam de sua relação com o verossímil, com os efeitos verossímeis. Se platonicamente pensadas, as imagens devem ser compreendidas segundo duas espécies, imagem icástica (Sofista, 234bc), proporcional ao paradigma ou à essência, e imagem fantástica, deformação ou desproporção da imagem icástica (Sofista, 235b, 236c). Corre aqui, lateralmente, o conceito horaciano de decorum, que prescreve para a obra poética clareza, justeza e recusa de todo e qualquer hibridismo e, mesmo, qualquer incongruência. Entretanto, como se sabe, nem tudo é tão simples. Vale reproduzir aqui a pequena alegoria narrada por Emanuele Tesauro em um texto de 1625 intitulado Il Giudicio. Dois célebres artífices atenienses, Fídias e Alcmene, receberam como encomenda uma cabeça de Palas Atena. A escultura do primeiro motivou o riso entre os jurados e a do segundo admiração: a cabeça esculpida por Fídias foi julgada grosseiramente esboçada, contrariamente àquela de Alcmene, cujas linhas foram consideradas finamente delineadas. Como conta Tesauro, Fídias, arguto inventor, pediu que as cabeças fossem colocadas longe, sobre duas colunas elevadas. Resultado: sua cabeça de Palas Atena pareceu bastante bela, pois que a distância lhe havia conferido proporção adequada, e a de Alcmene grosseira e mal formada. Isto equivale a dizer que é possível que a imagem fantástica, em função de determinada distância, que pode ser física e que pode ser igualmente intelectual, torne-se imagem icástica e vice-versa. Como resume de modo bastante pertinente João Adolfo Hansen,

a desproporção fantástica pressupõe, mimeticamente, o ponto de vista icástico que

a proporciona como desproporção: ela só é fantástica como uma das séries da

relação, ou seja, é um efeito, ou um diferencial (Hansen, 1995: 207).

6 Viseiras, pois, aristotélicas, que não permitem ver senão uma só res, res regrada tão somente pelo verossímil, verossímil que rejeita tudo o que pareça escapar ao natural e que, por isso mesmo, se torne afetado. Ora, na verdade, essa mesma res, poética, ficcional, pode oferecer diversos ângulos, lados diversos, diversas proporções, mesmo que despropositadas em suas proporções, mesmo que incongruentes em suas congruências. Eis porque Tesauro afirma que Fídias tinha o engenho mais agudo que o escalpelo, isto é, ordenado pelo juízo que pondera a deformação.

7 Emanuele Tesauro aponta para a necessidade de se considerar congruência(s) e incongruência(s), pois que tudo depende de como se vê, de onde se vê e, mesmo, do que se quer ver. Ora, a partir da segunda metade do século XVII, novos tipos de escritura romanesca ganham a cena literária francesa, e propõem outras referências ${ }^{5}$, outros mundos ficcionais possíveis, mundos como alternativa para aquele em que imperava uma ótica mimética. Diversas, aliás, serão as possibilidades de vozes, e, naturalmente, de "razões". Uma polifonia a qual faz precisamente alusão o je - que somente terá identidade 
(Monsieur Dyrcona) na segunda parte do volume -, que abre a primeira parte de L'Autre Monde ou les Estats et Empires de la Lune:

La lune estoit en son plain, le Ciel estoit descouvert et neuf heures au soir estoient sonnées lorsque nous revenions d'une maison proche de Paris, quatre de mes amys et moy.

Les diverses pensées que nous donna la veue de cette boulle de saffran nous desfrayerent ${ }^{6}$ sur le chemin; les yeux noyez dans ce grand astre, tantost l'un le prenoit pour une lucarne du ciel par où l'on entrevoyoit la gloire des bienheureux, tantost l'autre protestoit que c'estoit la platine où Diane dresse les rabats d'Appolon, tantost un autre s'escrioit que ce pourroit bien estre le Soleil luy mesme qui s'estant au soir despouillé de ses rayons, regardoit par un trou ce qu'on faisoit au monde quand il n'y estoit plus: et moy, dis-je, qui souhaite mesler mes entousiasmes aux vostres, je croys sans m'amuser aux imaginations pointuës dont vous chatouillez le temps pour faire le faire marcher plus viste, que la Lune est un monde comme celuy-ci à qui le nostre sert de Lune (Bergerac, 1977: 359).

8 Se uns e outros oferecem suas perspectivas sobre o que seria aquela "boulle de saffran" unicamente no intuito de "dréfayer la compagnie", o je confere à sua um caráter de seriedade que inseriria o romance em uma outra referência, quiçá a contrario, daquela até então considerada como veraz e, por isso mesmo, tomada como doxa. Que não se perca de vista: L'Autre Monde, em consonância, aliás, com outros textos seiscentistas, torcem o pescoço da fabula, entendida segundo sua visada aristotélica, isto é, segunda uma referência mimética a um único mundo - "nosso" mundo -, e acabam por fazer "émerger un nouveau style de positionnement logique pour la fiction, un nouveau style de fictionnalité"7. Neste sentido, o que passaria por ser, na pior das hipóteses, uma "creance burlesque" e, na melhor das hipóteses, uma falácia ou uma falsidade - que a Lua é [como] um mundo como outro qualquer e, ainda mais, que a Lua seria a Terra e que a Terra se tornaria Lua... torna-se não apenas uma possibilidade mas, sobretudo, uma verdade.

Verdade, sobretudo, para aquele cujo "Esprit [...] en son vol nul obstacle n'arreste" e que “ descouvre un autre monde a nos ambitieux". São estes dois dos quatorze versos que, de certa maneira, atuam como ex-ergon não apenas de todo romance, mas dos estados e dos impérios que eles representam ou referenciam. Além disso, os versos liminares, que têm o significativo título Autre du mesme au mesme, convocam o leitor ${ }^{8}$ - que intratextualmente é um auditor, "Mais escoutte, Lecteur [...]" - a fim de ratificar uma nova lógica narrativa, de dar credibilidade à nova empreitada ficcional e, igualmente, de ganhar a adesão à história contada 9 . Ao lado da figura do leitor feito interlocutor, comparece, à maneira de uma prova persuasiva, a figura do filósofo Girolamo Cardano: após o passeio sob o luar, a voz narrativa retorna à sua casa e lá se depara, sobre a mesa, com

un Livre ouvert que je n'y avois point mis: C'estoient les oeuvres de Cardan ${ }^{10}$, et quoy que je n'eusse pas dessein d'y lire, je tombé de la veue comme par force justement dans une histoire que raconte ce Philosophe; Il escrit qu'estudiant um soir à la chandelle, il apperceut entrer, à travers les portes fermées de sa chambre, deux grands vieillards, lesquelz apres beaucoup d'interrogations qu'il leur fit respondirent qu'ils estoient habitans de la Lune [...] (Cyrano, 1977: 360).

10 Para além do claro poder do livro que aqui se enuncia - e que se tornará o Livro por excelência, do qual se fará o processo, convocar a figura de Cardan, julgado pela Inquisição por suas idéias controversas e ímpias, significaria tomá-lo como interlocutor reiterativo de ficções que subvertem não apenas o modus operandi do literário mas, em filigrana, aquele de uma cosmogonia tirânica e autoritária - subtrair-se "à la tyrannie de l'authorité" é leitmotiv, lembre-se, da voz escritural conhecida como Cyrano de Bergerac. Neste sentido, recorrer ao que se enuncia ali como um argumento de autoridade, o 
fantástico de "un si beau voyage" à Lua imigraria para o icástico de uma aventura cuja narração em primeira pessoa nada apresentaria de inverossímil. Tanto mais porque o relato da chegada ao céu e ao mundo da Luaque, não por acaso se principia pelo dêitico “ voicy", que convida o leitor-interlocutor quase que a ver o acontecimento, à maneira quiçá de testemunha - constrói para si uma lógica narrativa que propõe possibilidade verossímil de outros mundos ${ }^{13}$. Não se pergunta a voz narrativa "Et pourquoy non?"? Para logo em seguida acrescentar, em mais um argumento de autoridade, que "Promethée fut bien autrefois au Ciel dérober du feu" (Bergerac, 1977:360).

11 É verdade que antes de sua chegada à Lua e ao Sol, o je que empreende a viagem a outro mundo conhece alguns malogros: seu cinto (figura 1) de "fioles pleines de Rosée"14 (Bergerac, 1977: 360) postos em movimentação pelo calor do Sol em direção o céu somente o desloca da França para o Canadá.

Figura 1 - Gravura da edição de 1657 de Histoire comique des Etats et Empires de la Lune

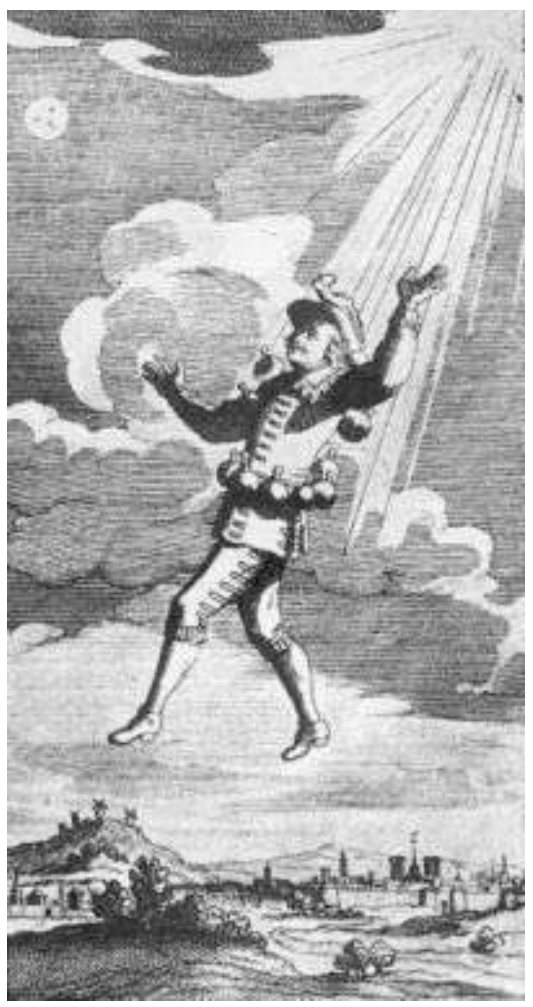

Seja como for, a entorse à verossimilhança principia já neste primeiro episódio. Nesta que é a "Nouvelle France" - que não seria quiçá outro mundo senão aquele de uma França originária-, o je depara-se com um "grand nombre de Sauvages", com uma "compagnie de soldats tambour battant" e com Monsieur de Montmagnie (Bergerac, 1977: 361). Pelo intermédio deste último, padres jesuítas tornam-se instâncias discursivas que entretêm com o mundo uma relação diversa daquela do narrador em primeira pessoa. 0 embate que se institui entre je e seu(s) interlocutor(es) diz respeito ao movimento, ou não, do Sol ao redor da terra. Causa espécie ao segundo a posição do primeiro, essencialmente porque ela fugiria ao senso comum partilhado na Nouvelle France:

[...] quelles grandes vraissemblances aves vous pour vous figurer que le Soleil soit immobile, quando nous le voyons marcher, et que la terre tourne autour de son centre avec tant de rapidité quand nous la sentons ferme dessous nous? (Bergerac, 1977: 362). 
13 A passagem acima aponta para o que está realmente em jogo em L'Autre Monde: as diversas maneiras de se entender o mundo e de sobre ele falar. Tanto mais se se acreditar que, graças ao discurso do je, "le monde [est] infiny [et] que l'Eternité n'est rien autre chose qu'une durée sans bornes et l'infiny une estendue sans limites" (Bergerac, 1977: 364). Tudo é então uma questão de perspectiva, à maneira, faça-se a hipótese, da disputa entre Fídias e Alcmene: uma assertiva verdadeira - a Terra que gira ao redor do Sol - pode deixar de sêlo, depende do juízo e da crença dos juízes. Entretanto, delineia-se em filigrana pelo discurso deste je um decisivo matiz retórico: no interior mesmo do inverossímil de uma viagem que transporta com a ajuda de um maquinário ainda mais inverossímil um corpo humano, busca-se persuadir seu interlocutor acerca do verossímil e do verdadeiro daquela que parece ser uma inverossímil concepção de mundo.

Ora, o ruído na significação e, por conseguinte, no significado parece decorrência de lógicas discursivas diversas: para o je, a Terra gira ao redor do Sol; para Monsieur de Montmagnie, e, por inferência, para os padres jesuítas, dos quais ele seria o porta-voz, o discurso do primeiro não pode ser considerado. Que se permita aqui um excursus terminológico. Para o Dictionnaire Universelle de Antoine Furetière, mágico é um “ enchanteur, celuy qui fait des effets des choses extraordinaires par la puissance diabolique". Se a acepção copernicana defendida no episódio da Nouvelle France pelo viajante não pode ser tomada como verdadeira é porque os padres jesuítas julgam que ela seria proferida por alguém habitado por uma força diabólica. Se não por um mágico, por um impostor ${ }^{15}$. Segundo Furetière, um impostor é um "trompeur, affronteur, calomniateur" - e impostura é “ tromperie, mensonge, calomnie". Na Nouvelle France, este je não passaria então de um sofista, cuja argumentação se preocupa não com a verdade mas tão somente com a eficácia persuasiva. Sofista, ainda, porque o que encena é a astúcia discursiva, toda centrada no hábil manuseio da linguagem ${ }^{16}$. Sofista, enfim, porque apregoa em substância o relativismo do mundo. Seja como for, e a se seguir passo a passo o diálogo entre je e Monsieur de Montmagnie, nota-se que todo ele é pontuado por certa indisposição de espírito em ratificar razões contrárias não apenas ao topos em vigor na Nouvelle France mas, igualmente, em franca oposição a autoridades tidas como incontestáveis. Assim, lemos, por exemplo:

Ce qui faict que je ne suis pas bien fort de vostre opinion, c'est qu'encore hier vous fussiés party de Paris, vous pouvés estre arrivé aujourdhuy en cette contrée, sans que la Terre ayst tourné, car le Soleil vous ayant enlevé par le moyen de vos bouteilles ne doit-il pas vous avoir amené icy, puisque selon Ptolomée, Ticobrae et les Philosophes modernes, il chemine de biais que vous faites marcher la terre? (Bergerac, 1977: 362).

Há, ainda, intervenções que dão conta da dificuldade hermenêutica de Monsieur de Montmagnie em aceitar o que para o je é uma verdade - o inverso não seria igualmente válido? fica aqui a interrogação. Como na passagem em que lhe é difícil crer que o mundo seria "infinito" a se considerar a argumentação de seu interlocutor viajante:

Mais, me dit-il, si comme vous asseurés les Estoilles fixes sont autant de Soleils, on pourroit conclurre de la que le monde seroit infiny, puisqu'il est vray semblable que les Peuples de ces mondes qui sont autour d'une Estoille fixe que vous prenes pour un Soleil, descouvrent encore au dessus d'eux d'autres Estoilles fixes que nous ne sçaurions appercevoir d'icy, et qu'il en va eternellement de cette sorte (Bergerac, 1977: 364);

Ma foy, me replicqua-t-il, vous aves beau dire, je ne sçaurois du tout comprendre cet infiny (Bergerac, 1977: 364). 
Geocentrismo ou heliocentrismo, pouco importa. O que parece definitivamente relevante no episódio da Nouvelle France é o jogo entre a verdade e a falácia, entre o raciocínio verdadeiro e o raciocínio caviloso.

Importa igualmente lembrar que, para os ocupantes ortodoxos da Nouvelle France, se se fosse aceitar o fato de que a terra se movimenta, Monsieur de Montmagnie creria em um padre jesuíta que explicara o fenômeno não no sentido (heterodoxo) da ciência, mas segundo a doxa da religião:

En effet, disoit il, je m'imagine que la Terre tourne, non point pour les raisons qu'allegue Copernic, mas pour ce que le feu d'Enfer, ainsy que nous apprend la Saincte Ecriture, estant enclos au centre de la terre, les Damnez qui veulent fuir l'ardeur de la flame, gravissent pour s'en esloigner contre la voute, et font ainsy tourner la Terre, comme un chien faict tourner une roue lors qu'il court enfermé dedans (Bergerac, 1977: 363). ". Sua chegada é, à primeira vista, das mais desastrosas, pois que, depois do vôo tornado possível graças a uma máquina construída para estes fins, sua queda se termina sobre uma árvore, "justement l'Arbre de la Vie". O romance ganha aqui em habilidade poética: a figura da descrição, essencialmente a topografia, é das mais coloridas, convidando todos os sentidos a desfrutarem do panorama que se vislumbra. A passagem é longa, mas merece ser citada in extenso:

A peine, quand je fus relevé, eus-je remarqué les bords de la plus large des quatre grandes rivieres qui forment um lac en la bouchant, que l'esprit ou l'ame invisible des simples qui s'exalent sur cette contrée me vint resjouir l'odorat; les petits caillous n'estoient rabotteux ny durs qu'à la veue, ils avoient soin de s'amolir quand on marchoit dessus.

Je rencontré d'abord une Estoille de cinq avenues dont les chesnes qui la composent sembloient par leur excessive hauteur porter au ciel un parterre de haute fustaye [...] La de tous costez, les fleurs, sans avoir eu d'autres jardiniers que la nature, respirent une haleine sauvage qui resveille et satisfaict l'odorat; la l'incarnat d'une rose sur l'esglantier et l'azur esclatant d'une violette sous des ronces [...] vous font juger qu'elles sont touttes deux plus belles l'une que l'autre; la le printemps compose touttes les Saisons; la ne germe point de plante veneneuse que sa naissance trahisse sa conservation; la les ruisseaux racontent leurs voyages aux caillous; la mille petittes voyx emplumées font retentir la forest au bruit de leurs chançons, et la tremoussante assemblée de ces gosiers melodieux est si generalle qu'il semble que chacune fueille dans le bois ayst pris la langue et la figure d'un rossignol [...] A costé de ce bois se voyent deux prairies, dont le vert guay continu faict une emeraude à perte de veue. Le meslange confu des peintures, que le printemps attache à cent petittes fleurs, esgare les nuages l'une dans l'autre et ces fleurs agitées semblent courir aprés elles mesmes pour eschapper aux caresses du vent; on prendroit chaque prairie pour un ocean [...] Au milieu d'un tapis si vaste et si parfaict, court à bouillons d'argent une fonteine rusticque qui couronne ses bords d'un gason esmaillé de pacquerettes, de bacinets, de viollettes, et ces fleurs qui se pressent tout à l'entour font croire qu'elles se pressent à qui se mirera la premiere [...]; les animaux qui s'y venoient desalterer, plus raisonables que ceux de nostre monde, tesmoignoient estre surpris de voir qu'il faisoit grand jour sur l'orison pendant qu'ils regardoient le Soleil aux antipodes et n'osoient casi se pencher sur le bord de crainte qu'ilz avoient de tomber au firmament (Bergerac, 1977: 368) ${ }^{17}$.

Da longa passagem acima citada, dois elementos merecem ser destacados, pois que contribuem essencialmente para a construção do verossímil de mais um episódio romanesco com aparência inverossímil. Recorrer seis vezes ao dêitico "la" e igualmente 
seis vezes a termos ligados ao registro semântico da visão - voyent, veue, mirera, tesmoignoient $^{18}$, voir, regardoient - significaria criar as condições para a adesão do leitor: convidá-lo a ver os detalhes de uma precisa espacialidade é dar foros de verdade ao que é descrito, é conferir materialidade ao que pareceria ser apenas simulacro; é, em suma, colocar sob os olhos de um leitor extra-diegético o que apenas os olhos de um je narrativo (pretensamente) viu. Mais do que simples descrição, a chegada à Lua revela-se perfeita hipotipose - e sabe-se, sobretudo graças a Quintiliano, o quanto a hipotipose encena a verossimilhança em razão seus poderes de visualização -; é ela, outrossim, que permite ao leitor reconstituir o espaço descrito de maneira clara e viva, como se ele próprio estivesse sentado nos galhos da árvore. A habilidade da descrição cyraniana reside precisamente aí: em reter o olhar do leitor ou solicitar, indiretamente, que ele se detenha. Além disso, é relevante notar que a passagem principia pelo emprego do verbo "remarquer". A se consultar o dicionário seiscentista Le Thresor de la langue françoyse (1606), não surpreende que seu autor Jean Nicot defina o termo como "adiicere oculum" ${ }^{20}$, isto é, lançar os olhos sobre alguma coisa. Em substância, é graças ao olhar que vê e que (d)escreve o que vê - e " à la veue de tant de belles choses" como que conclui a descrição da Lua - que se atribui ao que se viu e ao que se (d)escreveu matiz verossímil, no interior mesmo da inverossimilhança.

Neste sentido, não seria inoportuno afirmar que a construção dos mundos em Cyrano seria balizada por uma "antropologia relativista", segundo os termos de Michèle Rosellini (2005:8), que não apenas dá a conhecer o Mundéo comum entre ${ }^{21}$ os historiadores da literatura falar em dimensão heurística (e por isso sua dimensão cognitiva) da ficção cyraniana em geral e de L'Autre Monde em particular -, mas que igualmente apresenta uma experimentação do ficcional. É o que parece se dar no episódio da "Província dos Filósofos", na segunda parte do romance, em "les Estats et Empires du Soleil". Se a viagem à Lua tinha como objetivo último ratificar a hipótese copernicana do heliocentrismo ${ }^{22}$, o programa filosófico(-ficcional) que subjaz à viagem ao Sol é dos mais complexos: como bem resume Michèle Rosellini,

il s'agit de redefinir la hiérarchie des facultés de l'âme, d'arracher l'imagination au rôle subalterne qu'elle occupe, après l'entendement et la mémoire, dans la psychologie aristotélicienne. [L'imagination] pour Cyrano est un instrument de connaissance, une voie vers la vérité (Rosellini, 2005: 11).

Vejamos, então. Enclausurado em razão das obscuras intrigas do cura de Colignac, Dyrcona constrói uma "grande boiste fort legere [Figura 2] [...]; le vase estoit construit exprés à plusieurs angles, et en forme d'icosaëdre, afin que chaque facete estant convexe e concave, ma boule produisit l'effet d'um miroir ardent" (Bergerac, 1977: 443), escapa de sua cela e voa em direção do Sol. 
Figura 2 - Gravura da edição de 1662 de Histoire comique des Etats et Empires du Soleil

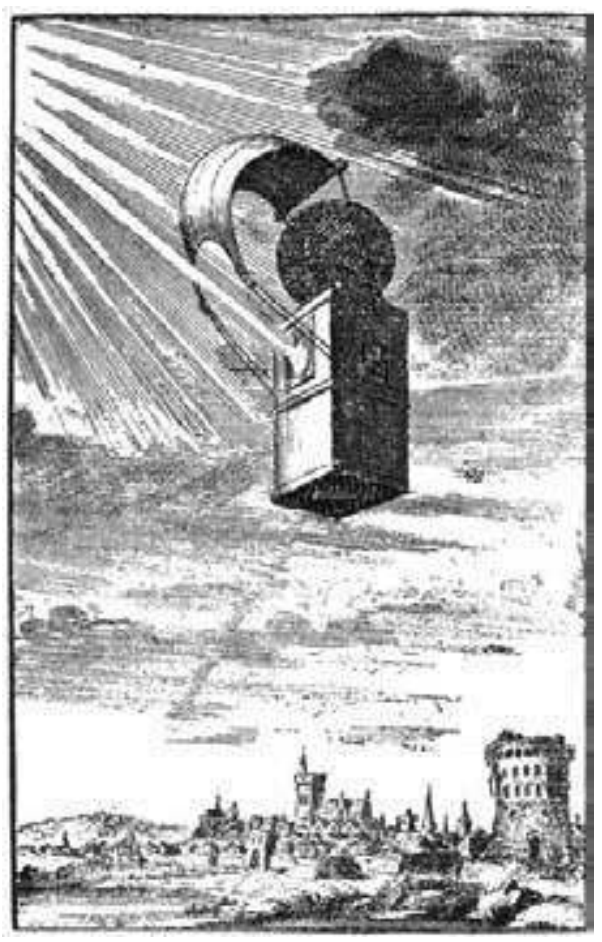

22 Ali conhecerá um "Viiellard fort venerable" que observava com grande atenção um duelo entre as figuras da Salamandre e da Remore. O ancião acabará por se apresentar como Campanella, “Calabrois de Nations" (Bergerac, 1977:492), que atuará como uma espécie de guia intelectual22, de figura iniciática que mostra ao viajante o mundo do Sol - não por acaso Roger Chartier (Chartier, 2007: 181) observa que Campanella "desempenha nos Estados e Impérios do Sol o papel do demônio de Sócrates no romance anterior".

A peregrinação à Província dos Filósofos ganha relevo hermenêutico precisamente em razão do papel que ali assume a imagem, cuja natureza a inseriria no gênero fantástico. No lugar da verborragia e do logos-rei dos filósofos que habitam a Terra, a língua dos Filósofos lunares é afásica. Tudo, idéias e sensações, manifestam-se por meio de imagens. Reina ali a imagerie, que sabe pintar os (des)caminhos da memória, da imaginação, do juízo, dos afetos:

La plus grande part de Philosophes ne parlent pas avec la langue; mais quand ils veulent communiquer leur pensée, ils se purgent par les élans de leur fantaisie d'une sombre vapeur, sous laquelle ordinairement ils tiennent leurs conceptions à couvert; et si-tost qu'ils ont fait redescendre en son siege cette obscurité de rate qui les noircissoit, comme leur corps est alors diafane, on apperçoit à travers leur cerveau, ce dont ils se souviennent, ce qu'ils imaginent, ce qu'ils jugent; et dans leur foye et leur coeur, ce qu'ils desirent et ce qu'ils resolvent: car quoy que ces petits portraits ${ }^{24}$ soient plus imperceptibles qu'aucune chose que nous puissions figurer, nous avons en ce Monde cy les yeux assez clairs pour distinguer facilement jusqu'aux moindres idées (Bergerac, 1977: 501).

24 Não surpreende, pois, que na Província dos Filósofos reine "non pas un discours articulé mais une histoire en tableaux de toutes [leurs] pensées" (Bergerac, 1977: 501). A Província dos Filósofos põe assim em cena uma linguagem que apela essencialmente a seus atributos de visualidade. Libertos da opacidade que os constrangia na Terra, unidos à "source du jour" que é o Sol, todos estão aptos a comunicar suas idéias, seus pensamentos, seus juízos e 
suas sensações sem recorrer à linguagem ordinária. Na Província dos Filósofos, faça-se aqui a hipótese, tudo é claridade e clarividência. Mesmo fisicamente, as terras filosóficas reservam um lugar especial ao motivo da imaginação. Se tais terras são alimentadas por três rios - da Mémoire, da Imagination, do Jugement -, o segundo deles parece o mais agradável, em razão não apenas da tranqüilidade de sua correnteza e da coloração de suas águas, mas, igualmente, em virtude de sua vegetação e de sua fauna aquática:

Le Fleuve de l'Imagination coule plus doucement; sa liqueur legere et brillante étincelle de tous costez: Il semble regarder cette eau d'un torrent de bluettes humides, qu'elles n'observent en voltigeant aucun ordre certain. Apres l'avoir considerée plus attentivement, je pris garde que l'humeur qu'elle rouloit dans sa couche, etoit de pur or potable, et son écume de l'huile de Talc. Le Poisson qu'elle nourrit, ce sont des Remores, des Syrenes, et des Salemandres; on y trouve au lieu de gravier, de ces cailloux dont parle Pline, avec lesquels on devient pesant quand on les touche par l'envers, et leger quand on se les applique par l'endroit. J'y en remarquay de ces autres encor dont Giges avoit un anneau, qui rendent invisibles; mais surtout un grand nombre de pierres philosophales éclatent parmy son sable. Il y avoit sur les rivages force arbres fruitiers, principalement de ceux que trouva Mahomet en Paradis; les branches fourmilloient de Phénix [...] ${ }^{26}$ (Bergerac, 1977: 500).

Neste sentido, não seria inapropriado afirmar que, graças à imagem- e, se se quiser, à imaginação-, contrariamente à hierarquia cognitiva aristotélica, acede-se ao conhecimento e à verdade. A topografia a que mais uma vez se dedica Dyrcona atuaria como a imagem cyraniana de um pensamento/de um discurso mais brilhante, mais colorido. E, sobretudo, pouco afeito à ordem icástica.

L'Autre Monde a fluir como um rio da imaginação? Sonho, devaneio do je viajante, de Dyrcona? Quem responde negativamente a tais questões, e de maneira definitiva embora recorra à figura do equívoco - é Campanella, a algumas linhas da conclusão de "Les Estats et Empire du Soleill": "Si vous appellez songe [...] ce que vostre ame peut voir avec autant de certitude, que vos yeux le jour quand il luit, je le confesse" (Bergerac, 1977: 506) ${ }^{27}$.

\section{BIBLIOGRAFIA}

ALCOVER, Madeleine (1970). La pensée philosophique et scientifique de Cyrano de Bergerac. Genebra: Droz.

ALCOVER, Madeleine (1990). Cyrano relu et corrigé. Genebra: Droz.

ARNAUD, Antoine e NICOLE, Pierre (1992). La logique ou l'art de penser. Paris: Gallimard.

BENVENISTE, Emile (1974). Problèmes de linguistique générale. Paris: Gallimard.

BERGERAC, Cyrano de (1977). Oeuvres complètes. Paris: Librairie Belin. CHARTIER, Roger (2007). Inscrever e apagar. São Paulo: Editora UNESP.

DEMORIS, René (1975). Le roman à la première personne. Du Classicisme aux Lumières. Paris: Colin.

FONTANIER, Pierre (1977). Les figures du discours. Paris: Flammarion. 
HANSEN, João Adolfo (1995). "Ut pictura e Verossimilhança na doutrina do Conceito no século XVII”. In: Para Segismundo Spina. Língua, Filologia e Literatura. São Paulo: Iluminuras/EDUSP.

KAHN, Didier (2006). “Les apparitions du Démon de Socrate parmi les hommes”. In: Harry, P., Mothu, e Sellier, Ph. Dissidents, excentriques et marginaux de l'Âge classique. Autour de Cyrano de Bergerac. Bouquet offert à Madeleine Alcover. Paris: Champion, p.483-550.

LEIRIS, Michel (1992). Journal. 1922-1989. Paris: Gallimard.

MARTINE, Jean-Luc (2005). Questions de styles, $n^{\circ} 2,2005$, p. 25-43, 8 mars.

NOILLE-CLAUZADE, Christine. Considérations logiques sur de nouveaux styles de fictionalité: les mondes de la fiction au XVIIe siècle. [Disponível 17/07/2010] <URL: http://w3.u grenoble3.fr/rare/spip/ IMG/pdf/Noille_-_mondes_possibles.pdf>.

PLATÃO. Diálogos (1972) São Paulo: Abril Cultural, 1972.

PREVOT, Jacques (1977). Cyrano de Bergerac romancier. Paris: Belin.

RACAULT, Jean-Michel (2003). Nulle part et ses environs: voyages aux confins de l'utopie littéraire classique (1657-1802). Paris: Presses de l’Université Paris-Sorbonne.

ROSELLINI, Michèle (2005). La poétique de la métamorphose chez Cyrano: jeux de l'illusion sensible ou fiction matérialiste [Disponível 09/07/2010] <URL: http://www.lastree.net/fragmentslog/ fragments/communication-Cyrano-MR.pdf>.

SERROY, Jean (1981). Roman et réalité. Les histoires comiques au XVIIeme. Paris: Minard.

SOLLERS, Philippe (2003). L'éloge de l'infini. Paris: Gallimard.

\section{NOTAS}

1. Em sua Lettre XIII (Lettres diverses), a voz autoral nos lembra que ela se "soustrait à la tyrannie de l'authorité" (Bergerac, 1977: 62).

2. Importa observar que em sua dedicatória ao Duc de Arpajon, Cyrano de Bergerac confessa que as Lettres não são senão um "ramas confus des premiers caprices, ou pour mieux dire des premieres folies de ma jeunesse" (Bergerac, 1977: 26). Confusão, caprichos, loucuras... outros tantos nomes de um arsenal poético impregnado por figuras que encenam a descontinuidade, a incongruência e o excesso e que dão o tom à obra de Bergerac: metáforas, alegorias, anáforas, perífrases, equívocos, etc.

3. Não é inútil lembrar a definição que Antoine Furetière, em seu Dictionnaire Universelle, oferece do termo: "POINTE, se dit figurément en choses spirituelles \& morales. La pointe de l'esprit s'émousse par la débauche continuelle. Ce jeune homme a beacoup de vivacité, de pointe d'esprit. Les Epigrammes doivent finir par quelque agreable pointe. Les pointes sont des equivoques, \& des jeux d'esprit. Il faut se donner de garde des fausses pointes, des turlupinades".

4. Sobre o viés cyraniano do gênero narrativa de viagem, que se confunde com aquele outro a emergir com vigor no século XVII, a histoire comique, consulte-se com extremo proveito René Démoris (1975) e Jean Serroy (1981), que não apenas aponta para as transformações operadas por Cyrano no gênero cômico como igualmente se interroga sobre a pertença do romance cyraniano à tradição das Utopias.

5. De modo sintético, e segundo os termos de Christine Noille-Clauzade, "dans la seconde moitié du XVIIe siècle, un nouveau type d'écriture romanesque apparaît, qui dénigre les 'vieux romans' précieux et instaure à la fois un format appelé à durer (le format bref: en un seul volume), une topique nouvelle (l'histoire servant de 'cadre' à la fiction galante) et peut-être une nouvelle façon de concevoir et de lire la 
fiction, un 'nouveau roman' qui, dépassant le sous-genre du 'roman historique', inaugurerait le x-ième renouveau de tout le genre romanesque" (Considérations logiques sur de nouveaux styles de fictionalité: les mondes de la fiction au XVIIe siècle. In: http://w3.u-grenoble3.fr/rare/spip/IMG/pdf/Noille__mondes_possibles.pdf., p.2. Acesso em 16 de setembro de 2010).

6. Vale relembrar o que o século XVII entende pelo verbo Dréfrayer, que apresenta íntima ligação, como ficará evidente, com o conceito de pointe. Assim, segundo o Dictionnaire de l'Académie Française em sua versão seiscentista, “On dit figur. \& fam. Défrayer la compagnie, pour dire, L'entretenir agréablement".

7. Christine Noille-Clauzade. Considérations logiques sur de nouveaux styles de fictionalité: les mondes de la fiction au XVIIe siècle.(In: http://w3.ugrenoble3.fr/rare/spip/IMG/pdf/Noille__mondes_possibles.pdf., p.16. Acesso em 16 de setembro de 2010).

8. Mesmo que este leitor seja um "semblable", como observa pertinentemente Jean-Luc Martine em Simulation et dissimulation dans Les États et empires de la Lune de Cyrano de Bergerac. Fiction de la rhétorique et rhétorique de la fiction (Martine, 2005: 30). Importa aqui, a este respeito, relembrar uma passagem do início de "Les Estats et Empires du Soleil", em que o je, recém-chegado a Toulouse de sua viagem à Lua, é instado por seu amigo Monsieur de Colignac a "rediger par écrit" as coisas "extraordinaires" que lhe foram contadas. A acolhida ao Livro, intitulado Les Estats et Empires de la Lune, foi notável, ganhando para si um amplo e variado leitorado, do "Gentilhomme jusqu'au Moine", passando mesmo pelas mulheres. Um sucesso semelhante leva a voz narrativa a dividir seu público-leitor em duas categorias, os "ignorants" e "idiots", e os "habiles". Como era de se supor, os primeiros consideram a obra "un pot pourry de contes ridicules, un amas de lambeaux décousus, un repertoire de peu d'Asnes à bercer les enfans; et tel n'en connoist pas seulement la sintaxe, qui condamne l'Auteur à porter une bougie à S.Mathurin" (Bergerac, 1977:425-426).

9. A apóstrofe endereçada ao leitor faz-se igualmente presente em Les Entretiens Pointus. Trata-se, ali, de caucionar uma nova disposição discursiva e, a fortiori, uma nova poética ficcional. Após definir a noção de pointe, a voz prefacial interpela o leitor nos seguintes termos: "C'est pourquoy, Lecteur, ne blasme point ces contrarietez et faussetez manifestes qui se trouverront par fois en ces Entretiens, on n'a voulu que se divertir; et tant de beaux Esprits qui tiennent icy leur rang, se traittant icy par fois les uns les autres, et souvent eux-mesmes, de stupides et d'insensez, témoignent assez qu'ils ne veulent pas estre creux, mas seulement admirez, et que ce plaisir est leur seul objet. Suy donc leurs intentions, mon cher Lecteur, et sans éplucher les choses, prens part à leurs Divertissemens, qui te seront agreables ou dégoutants, selons que tu leur seras semblable ou dissemblable” (Bergerac, 1977: 17). “ Semblable" "dissemblable"? É evidente que o leitor a que se dirige Cyrano não fez senão sorrir... pois o que se enuncia aqui é não apenas um pacto entre leitor-auditor e voz autoral mas, igualmente, uma inegável cumplicidade.

10. Segundo Roger Chartier, não há dúvidas de que o livro de Cardan é o De la Subtilité et des subtiles inventions, publicado em 1550 e traduzido para o francês a partir de 1556.

11. Após seu retorno à Terra, je e dois de seus amigos, o Conde de Colignac e o marquês de Cussan, decidem deixar as terras do primeiro e partir para aquelas do segundo. Para "enrichir [son] ame avec plus de loisir des liberalitez de [sa] veuë", je se faz acompanhar de "quelques Livres", de uma "petite Bibliotheque" (Bergerac, 1977: 431), que empreendem ao enredo e à matéria discursiva de L'Autre Monde toda sua conotação livresca e sua marca de auctoritas. Segundo Philippe Sollers, tratar-se-ia de "l'épanchement des livres dans la vie réelle, un phénomène qui commence peu à peu à faire sens, vérité, actualité, à partir de l'archive. C'est le projet de Bergerac" (Sollers, 2003: 1102). "Projeto" que se faz no interior de uma "tessitura livresca", como bem define Jacques Prévot (1977: que organiza a narração a partir de uma visada mais ampla, aquela de um mundo multiforme da escrita.

12. Eis porque Madeleine Alcover (1970) nos convida a descobrir na obra de Cyrano de Bergerac a manifestação de uma escrita que se recusa a aderir a quaisquer sistemas. 
13. Sobre o "alhures" em Cyrano, é incontornável a leitura de Jean Michel Racault (2003).

14. Cyrano apropriar-se-ia aqui de um episódio de Orlando o Furioso, de Ariosto: no canto XXXIV ("As harpias na Itália, Astolfo na lua"), depois de sua descida aos Infernos para impedir que as harpias de lá saíssem para atacar o Preste João, o cavaleiro inglês Astolfo, primo de Orlando, ruma à Lua acompanhado pelo evangelista e montado em seu cavalo Hipogrifo. Vale assinalar que a Lua apresenta-se para Ariosto como o Paraíso, local onde se encontram todas as coisas perdidas na Terra. Como o juízo de Orlando que lhe foge ao tomar conhecimento do casamento de Angélica com o sarraceno Medor-, que é descoberto por Astolfo em uma ampola e em seguida devolvido a seu dono.

15. Relembre-se que quando o viajante chega a Toulouse, após sua estadia na Lua, e é recebido por Monsieur de Colignac, este último recebe a visita de um grupo de veneráveis que estão à procura de um "Sorcier" que ali estaria hospedado; seu interesse é aquele "de le faire brûler sans scandale". Ora, se as mãos vindicativas da Inquisição assombram neste momento é porque o autor de Les Estats et Empires de la Lune não pode ser senão considerado um Sorcier, já que é impossível explicar sua ascensão à Lua sem a "entremise de..." e não se ousa nomear "la beste". Além disso, este Sorcier, ao que contam, fora acompanhado em suas peregrinações pelo mundo da Lua do demônio de Sócrates! Assim, se não Sorcier, na melhor das hipóteses "le plus grand Magicien de l'Europe" (Bergerac, 1977: 426). Vale ainda lembrar que à "Harangue" dos "neuf ou dix Barbes à longue robe" Monsieur de Colignac não respondia senão com "haaaa, ou des hoooo" (Bergerac, 1977: 427) - sua atitude ratificaria certa jocositas que se insinua em filigrana. 0 je narrativo, por sua vez, após a saída dos Inquisidores que desejam levá-lo à fogueira, não profere "je serois fort joyeux de consentir à la tentation qui me suggere de ne leur laisser em cette Province que mon Portrait"? A imagem no lugar da coisa... a fogueira será a mesma... Sobre os diferentes retratos gravados de Cyrano, consulte-se Madeleine Alcover (1990).

16. Donde a suspeita que Platão faz pairar sobre os sofistas: “- Estrangeiro: Não devemos admitir que também o discurso permite uma técnica por meio da qual se poderá levar aos ouvidos de jovens ainda separados por uma longa distância da verdade das coisas, palavras mágicas, e apresentar, a propósito de todas as coisas, ficções verbais, dando-lhes assim a ilusão de ser verdadeiro tudo o que ouvem e de que, quem assim lhes fala, tudo conhece melhor que ninguém? [...] E, para voltar ao sofista, dize-me: já está claro que se trata de um mágico que somente sabe imitar as realidades [...] Devemos, pois, situa-lo como mágico e imitador" (Sofista, 234c e 235a). A mesma suspeita sobre os sofistas se lê no princípio Dos argumentos sofísticos, de Aristóteles: “a arte sofística é o simulacro da sabedoria sem a realidade, e o sofista é aquele que faz comércio de uma sabedoria aparente, mas irreal" I(165a 20-25). O Dictionnaire Universel de Antoine Furetière esclarece que o termo, "autrefois honorable" e que "signifioit simplement [...] Professeur d'Eloquence" e que era atribuído "indifferement à tous ceux qui étoient excellents en quelque art ou science que ce fust", tornou-se "maintenant odieux"; na acepção negativa de Furetière ecoa a definição aristotélica: sofista é "celuy qui fait des surprises dans l'argumentation, qui a dessein de tromper ceux qu'il veut persuader" - relembre-se que, nos mesmos Argumentos sofísticos, Aristóteles apontava para a impostura dos sofistas: "E assim exatamente como ao contar aqueles que não têm suficiente habilidade em manusear as suas pedrinhas são logrados pelos espertos, também na argumentação os que não estão familiarizados com o poder significativo dos nomes são vítimas de falsos raciocínios tanto quando discutem eles próprios como quando ouvem outros raciocinar" (165a 10-20).

17. Os negritos são meus.

18. Lembre-se que a figura grega da autopsia inscreve-se no mesmo registro daquela conhecida entre os latinos como evidentia: testemunhar é estar ou ter estado presente, é ser ou ter sido testemunha ocular. Mesmo que tais testemunhas sejam estes "animaux" que ali vão se desalterar. 
19. Nunca é demais lembrar algumas passagens canônicas dos Antigos a respeito de tal figura. Horácio afirma em De Arte Poetica que "o espírito é menos vivamente tocado por aquilo que o autor lhe confia ao ouvido do que por aquilo que lhe é colocado sob os olhos" (segnius inritant demissa per aurem quam quae sunt oculis subiecta fidelibus); Cícero, no registro da descrição de personagens, diz, no De Oratore, que "o mérito está em colocar as coisas tão bem sob os olhos, de tornar o caráter, a linguagem, a fisionomia do personagem tão expressivos que o auditor acredita vê-lo diante dele" (est autem haec hujus generis virtus, ut ita facta demonstres, ut mores ejus de quo narres, ut sermo, ut vultus omnes exprimantur, ut iis qui audiunt tum geri illa fierique videantur). Quintiliano enuncia, por sua vez, e de modo enfático em De Inst. Orat. VIII, 3,62, que "é uma grande qualidade aquela de apresentar as coisas das quais se fala com tal clareza que elas parecem estar sob nossos olhos. De fato, o discurso não produz um efeito suficiente e não exerce plenamente a impressão que deve exercer se seu poder se limita aos ouvidos e se o juiz acredita que para ele é feito tão somente o relato dos fatos que conhece em vez de coloca-los em relevo e de torná-los ostensivos aos olhos do espírito" (Magne virtus res de quibus loquimur clare atque ut cerni videantur enuntiare. Non enim satis efficit neque, ut debet, plene dominatur oratio, si usque ad aures valet, atque ea sibi iudex de quibus cognoscit narrari credit, non exprimi et oculis mentis ostendi).

20. O negrito é meu.

21. É afinal o que descobre o je ao empreender sua ascensão ao Sol: "Je connus tres distinctement, comme autrefois j'avois soupçonné en montant à la Lune, qu'en effet c'est la terre qui tourne d'Orient en Occident à l'entour du Soleil, et non pas le Soleil autour d'elle; car je voyois, en suite de la France, le pied de la bote d'Italie, puis la mer Mediterranée, puis la Grece, puis le Bosphore, le Pont-Euxin, la Perse, les Indes, la Chine, et enfin le Japon, passer successivement vis à vis du trou de ma loge; et quelques heures apres mon élevation, toute la mer du Sud ayant tourné, laissa mettre à sa place le continent d'Amerique.

Je distinguay clairement toutes ces revolutions, et je me souviens mesme que long-temps apres je vis encor l'Europe remonter une fois sur la Scene [...]" (Bergerac, 1977: 446). Será preciso chamar a atenção, uma vez mais, ao léxico (os negritos são meus) da visão a comparecer como testemunha? o que se vê não pode ser senão verdadeiro... Além do mais, je afirma que ele "distinguia claramente": o advérbio não precisa de explicações; o mesmo não pode ser dito do verbo “ distinguer", sobretudo para a língua do século XVII. Segundo o Dictionnaire Universel de Furetière, distinguir significa "Connoistre ou monstrer la difference d'une chose d'avec une autre", assim como toda ação de distinguir tem por objetivo "oster l'équivoque". Reforce-se, então: afirmar que distingue todas aquelas "revolutions" não apenas ratifica o acerto (e a modernidade) de sua perspectiva como a torna, em significativa operação de monstração, visível a todos.

22. Não surpreende que Dyrcona siga ou acompanhe o Vieillard Campanella sempre de modo bastante atento, sobretudo no que diz respeito "aux merveilles qu'il debitoit" (Bergerac, 1977: 492). Curiosamente, como se verá, os Filósofos habitantes do Sol não falam; impõe-se, pois, aqui a interrogação: Campanella, cuja voz é sempre ouvida, atuaria à maneira de um oráculo?

23. Para a figura do demônio de Sócrates, consulte-se com proveito Didier Kahn (2006: 483-550)

24. O negrito é meu.

25. O negrito é meu.

26. Talvez não tenha passado despercebida a presença da salamandra e da rêmora, a cujo combate Dyrcona e Campanella haviam assistido com interesse. Seres de natureza absolutamente contrária, a convivência no Rio da Imaginação da salamandra e a remore está em perfeita consonância com a perspectiva cyraniana do mundo, que oferece uma fisionomia multifacetada, por vezes paradoxal, por vezes contraditória, por vezes antitética. Ainda: não é caso de nos interrogarmos se a salamandra, símbolo da Alquimia e, segundo Paracelso, espírito elementar do fogo, não seria a imagem dos Filósofos lunares? Pois que são, como ela, "les esprits vitaux du Soleil, ce grand et parfait animal" Bergerac, 1977: 493)? Campanella lembra ainda a Dyrcona que "les anciens de nostre Monde [la] nommoient des 'Lampes ardentes' " (Bergerac, 1977:491) e que os olhos da salamandra são como "deux petits soleils" (idem, ibidem). Quanto à sereia, poder-se-ia supor que sua 
figura aponta para o caráter híbrido das diversas vozes cyranianas presentes ao longo do romance.

27. Michel Leiris parece concordar, séculos mais tarde, com o Campanella de Cyrano... Ao menos é o que registram suas anotações de dia 25 de julho de 1924, sexta-feira: "Je viens de lire L'Autre Monde de Cyrano de Bergerac. C'est une oeuvre littéralement étourdissante, et de quelle poésie! [...] Il faut avant tout avoir l'air bien réveillé, c'est le seul moyen de faire prendre pour des réalités les rêves qu'on raconte" (Leiris, 1992: 51).

\section{RESUMOS}

A posteridade literária bem o conhece, é verdade, em razão de seu grande nariz. Entretanto, tal nariz o permitiu farejar em conhecimento de causa algumas questões ligadas ao literário que são eminentemente modernas, e que chegam mesmo a ultrapassar o registro das Belas Letras do século XVII. Como negar, por exemplo, que os Les Entretiens Pointus lançam a suspeita sobre o unitário da verossimilhança dos gêneros icásticos? Como não reconhecer em L'Autre Monde, que projeta o leitor em estados que não são mais aqueles desse mundo terreno, a exuberância da lua e do sol literários mergulhados no genus phantasticum, em franca oposição, uma vez mais, ao gênero icástico? Esse artigo dá-se como objetivo percorrer os textos de Cyrano de Bergerac procurando ali sublinhar os elementos constitutivos de uma poética da ficção plenamente apoiada sobre a oposição, ora direta ora indireta, entre mimesis icástica tal qual concebida por Platão no Sofista e mimesis fantástica, oposição esta que abre o debate literário nesse século XVII percorrido pelas querelas sobre as possibilidades de uma ficção liberta dos cânones clássicos.

Literary posterity well knows Cyrano de Bergerac, we might admit, by reason of his big nose. However, such nose allowed him to smell consciously some eminently modern literary issues, overcoming seventeenth-century Fine Letters registry. How can we deny, for example, that Les Entretiens Pointus cast suspicion on the icastic verisimilitude? How not to recognize in L'Autre Monde, which projects the reader on states outer of terrestrial world, an exuberant literary Moon and Sun immersed in fantastic genre, openly opposed, once again, to the icastic genre? This article aims to examine some texts of Cyrano de Bergerac looking for the constituent elements of a poetic fiction fully supported on the direct or indirect opposition between icastic mimesis, as conceived in Plato's Sophist, and fantastic mimesis. Such opposition opens the literary debate in a century perpassed by the complaints on the possibilities of a fiction liberated from classic rules.

\section{ÍNDICE}

Palavras-chave: Cyrano de Bergerac, Gênero fantástico, Gênero icástico, Verossimilhança

Keywords: Cyrano de Bergerac, Fantastic genre, Icastic genre, Verisimilitude

\section{AUTOR}

\section{LEILA DE AGUIAR COSTA}

Universidade Federal de São Paulo 
leila.aguiar@unifesp.br 